DOI: https://doi.org/10.46296/gt.v4i7.0020

\title{
MALFORMACIONES DENTALES Y SU RELACIÓN CON LA SUCCIÓN NO NUTRITIVA EN NIÑOS.
}

\section{DENTAL MALFORMATIONS AND THEIR RELATIONSHIP WITH NON-NUTRITIVE SUCTION IN CHILDREN}

\author{
Acosta-Andrade Arison ${ }^{1 *}$; González-Pazmiño Lisbeth Jomaly ${ }^{2}$; Cevallos-Delgado \\ Ivonne Vanessa ${ }^{3}$; Cobeña-Zambrano Kathya ${ }^{4}$; Zevallos-Espinel Vielka Michelle ${ }^{5}$ \\ 1 Universidad Amistad de los Pueblos, RUDN. Moscú, Rusia. \\ 2, 3, 4, 5 Universidad Laica Eloy Alfaro de Manabí, ULEAM. Manta, Ecuador.
}

*Correo: arisondavidacosta@gmail.com

\begin{abstract}
Resumen
El preocupante aumento de la incidencia y prevalencia de los hábitos orales nocivos también conocidos como succión no nutritiva son aquellos que "constituyen una de las principales causas de alteraciones en los órganos y musculatura orofacial". Se elaboró una revisión bibliográfica en la cual se realizó una búsqueda en 4 bases de datos electrónicas Google Scholar, PubMed, Scielo y Medline, cuya antigüedad sea máxima de 5 años, incluidos artículos transversales descriptivos. Se busca identificar los hábitos de succión no nutritiva que producen malformaciones dentales en niños. Los artículos analizados reflejaron que el $71,9 \%$ de la población infantil presentó el mal hábito de la succión digital, el 17\% manifestó la práctica nociva de succión de biberón, mientras que en menor frecuencia el 11,1\% demostró una manía de succión de chupón, que al ser ejercida periódicamente afectará de igual magnitud que el resto de los hábitos orales nocivos. Mediante esta revisión se concluye que la succión digital es el hábito nocivo más frecuente, debido a que los padres buscan entretener a sus hijos. Estos hábitos provocan una serie de malformaciones dentales, entre las que encontramos la mordida abierta anterior, sobrepase aumentado, mordida cruzada posterior, paladar profundo, entre otros.
\end{abstract}

Palabras clave: Alteraciones; Alimentación; Lactancia; Desarrollo; Deglución.

\begin{abstract}
The worrying increase in the incidence and prevalence of harmful oral habits also known as nonnutritive suction are those that "constitute one of the main causes of organ alterations and orofacial muscles". A bibliographic review was produced in which a search was carried out in 4 electronic databases Google Scholar, PubMed, Scielo and Medline, whose age is no more than 5 years, including descriptive cross-sections. To identify non-nourishing suction habits that produce dental malformations in children. The articles analysed reflected that $71.9 \%$ of the children's population had the bad habit of digital suction, $17 \%$ manifested the harmful practice of bottle suction, while less often $11.1 \%$ showed a suckling mania, which, being applied periodically, will effect of the same magnitude as the other harmful oral habits. This review concludes that digital suction is the most common harmful habit because parents seek to entertain their children. These habits cause a series of dental malformations, including the previous open bite, increased overpase, posterior crosted bite, deep palate, among others.
\end{abstract}

Keywords: Alterations; Food; Breastfeeding; Development; Deglution.

Información del manuscrito:

Fecha de recepción: 16 de noviembre de 2020

Fecha de aceptación: 04 de enero de 2021

Fecha de publicación: 11 de enero de 2021. 


\section{Introducción}

Los hábitos orales nocivos también conocidos como succión no nutritiva son aquellos que "constituyen una de las principales causas de alteraciones en los órganos y musculatura orofacial" (Solís, 2018). Estos hábitos en los niños deben ser evitados, para que el infante y futuro adulto no presente molestias tanto estéticas como por los temas de salud bucal.

Se debe tener mucho cuidado con la succión no nutritiva ya que ésta, según Lima et ál. "proporciona a los niños sensaciones de bienestar, placer emocional, protección, confort y satisfacción; es un comportamiento común en los pequeños en varias poblaciones" (2019). Los infantes a través de la correcta lactancia materna sin realizar la inclusión de sólidos ni otros líquidos han demostrado disminuir el riesgo de muchas enfermedades entre ellas se pueden destacar: enfermedades infectocontagiosas, alergias alimentarias, asma, entre otras enfermedades.

Desde la perspectiva de Puga et ál. (2015) "la lactancia es un hábito estimulante ortopédico del crecimiento normal de los maxilares.
La posición de los labios y la lengua es diferente al succionar del seno materno que al hacerlo del biberón". Existen dos tipos de hábitos de succionar en odontología los cuales son, de la forma nutritiva, que consiste en la lactancia materna; y la no nutritiva, que es la succión digital, del chupón, y en algunas ocasiones del biberón.

Adicionalmente se puede expresar que "la evidencia científica actual demuestra que son muchos los beneficios de la lactancia materna, sobre cualquier otra forma de alimentación en el recién nacido." (González et ál., 2019).

\section{Metodología}

\subsection{Diseño}

Se elaboró una revisión sistemática de artículos científicos dedicados a la salud.

\subsection{Estrategia de búsqueda}

Las búsquedas de información se realizaron en cuatro bases de datos electrónicas, Pubmed, Google Schoolar, Scielo, Medline. Las búsquedas se efectuaron en los idiomas de inglés, español y portugués, teniendo como preferencia aquellos artículos en 
inglés, a continuación, se elaboró una búsqueda de revisiones sistemáticas en la Biblioteca Cochrane Plus.

\subsection{Criterios de inclusión y exclusión}

Con respecto a la búsqueda de información se incluyó documentos enfocados en estudios transversales descriptivos menos de 5 años de antigüedad. Excluimos los artículos que no incluían los criterios de inclusión.

\subsection{Análisis de los datos}

El análisis realizado se obtuvo de los datos obtenidos con respecto a estudios realizados a las madres con relación al conocimiento sobre el efecto que tienen la succión no nutritiva, también de la educación brindada con el fin de reconocer la importancia de la lactancia materna.

\section{Resultados y extracción de datos}

De los 70 artículos de estudios transversales descriptivos encontrados en buscadores (Scielo, Redalyc, Google Scholar, Cochrane Library), destacaron 12 artículos para la producción de esta revisión bibliográfica.

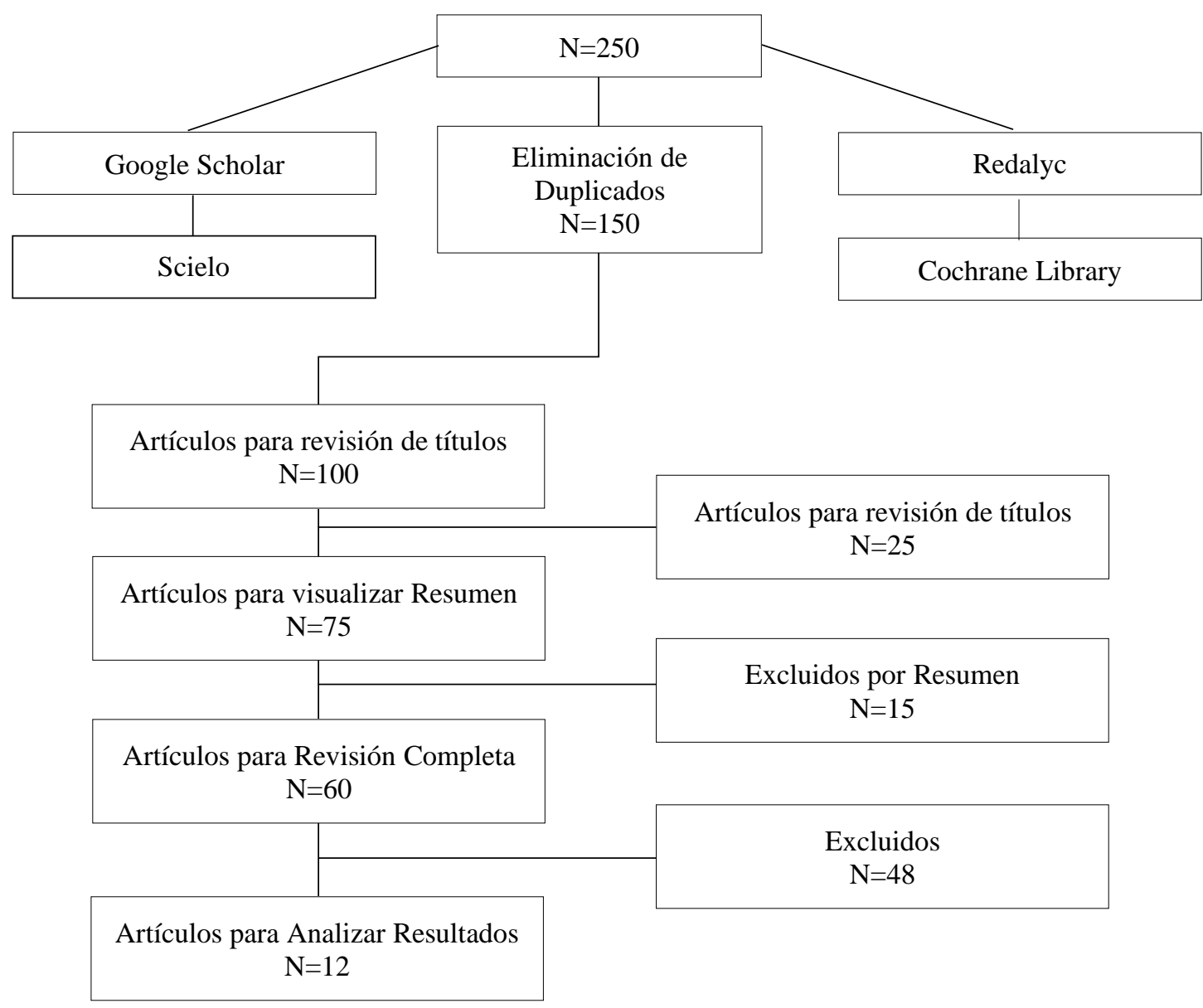


Tabla 1. Hábitos de succión no nutritiva

\begin{tabular}{|c|c|c|c|c|}
\hline $\begin{array}{c}\text { Autor/Año/Revi } \\
\text { sta }\end{array}$ & País & Diseño & Sujeto & Conclusiones \\
\hline $\begin{array}{c}\text { (Crespo Crespo, } \\
2020)\end{array}$ & Ecuador & Transversal & 185 niños & $\begin{array}{l}\text { El hábito de la succión digital } \\
\text { refleja un } 19 \% \text {, el cual trae } \\
\text { consigo consecuencias } \\
\text { dentomaxilares como la } \\
\text { mordida abierta. }\end{array}$ \\
\hline $\begin{array}{c}\text { (Silva Machado, } \\
\text { 2018) }\end{array}$ & Portugal & Transversal & $\begin{array}{c}326 \\
\text { lactantes }\end{array}$ & $\begin{array}{l}\text { Los lactantes que tenían hábitos } \\
\text { de succión no nutritiva } \\
\text { mostraron una mayor } \\
\text { prevalencia de maloclusión de } \\
\text { clase II. }\end{array}$ \\
\hline $\begin{array}{c}\text { (Adebanke } \\
\text { Kolawole, 2016) }\end{array}$ & Nigeria & Transversal & 992 niños & $\begin{array}{l}\text { Se concluyó que el mal hábito } \\
\text { de la succión del pulgar no es un } \\
\text { factor predisponente de caries } \\
\text { ni de mal higiene bucal. }\end{array}$ \\
\hline $\begin{array}{c}\text { (Bonnie Ling } \\
\text { 2018) }\end{array}$ & China & Transversal & 1114 niños & $\begin{array}{l}\text { Los niños que pasan de un año y } \\
\text { siguen con el hábito de succión de } \\
\text { chupete y succión del pulgar, tienen } \\
\text { más probabilidades de padecer } \\
\text { relaciones dentales anormales. }\end{array}$ \\
\hline $\begin{array}{c}\text { (Carrillo Valencia, } \\
\text { 2016) }\end{array}$ & Ecuador & Transversal & 435 niños & $\begin{array}{l}\text { No se encontró una relación entre } \\
\text { los hábitos de succión no nutritiva y } \\
\text { la presencia de maloclusiones en } \\
\text { niños. }\end{array}$ \\
\hline $\begin{array}{c}\text { (Paolantonio, } \\
\text { 2019) }\end{array}$ & Italia & Transversal & 1616 niños & $\begin{array}{l}\text { En caso de tener algún tipo de clase } \\
\text { de maloclusión, los malos hábitos } \\
\text { podrían agravarlo, por lo que deben } \\
\text { de ser prevenidos. }\end{array}$ \\
\hline $\begin{array}{c}\text { (González Martin, } \\
\text { 2020) }\end{array}$ & Cuba & Transversal & 80 niños & $\begin{array}{l}\text { Se pudo observar que la mayoría de } \\
\text { los niños no cuidaban muy bien de } \\
\text { su salud bucal y presentaban } \\
\text { hábitos deformantes. }\end{array}$ \\
\hline $\begin{array}{c}\text { (Silvestrini Biavati, } \\
2016)\end{array}$ & Italia & Transversal & 235 niños & $\begin{array}{l}\text { Se llegó a la conclusión de que los } \\
\text { hábitos de succión no nutritiva junto } \\
\text { con la mala alimentación, producen } \\
\text { una mordida abierta anterior. }\end{array}$ \\
\hline (Chen, 2016) & China & Transversal & 734 niños & $\begin{array}{l}\text { Los niños que fueron alimentados } \\
\text { por medio del biberón por más años } \\
\text { de lo normal, fueron más } \\
\text { vulnerables a desarrollar } \\
\text { características dentales anormales. }\end{array}$ \\
\hline
\end{tabular}

En un estudio realizado en 185 niños concluyo que la succión digital es el hábito más frecuente que conlleva a las anomalías dentomaxilares como la mordida abierta y según Silvia (2018) "los lactantes que tienen hábitos de succión no nutritiva tienden a presentar maloclusión clase II" pág. 4. Además, en otra investigación transversal se mencionó que los niños que pasan de 1 año y siguen practicando la succión del chupete y la succión del pulgar son más propensos a tener maloclusión (Bonnie Ling, 2018).

Sin embargo, es importante mencionar que en un estudio 
transversal realizado en 922 lactantes en Nigeria se evidenció que la succión del pulgar no se considera como un factor predisponente de caries ni de mala higiene bucal (Adebanke Kolawole, 2016), pero está en relación con la presencia de maloclusión en los niños (Carrillo Valencia, 2016). En el caso de presentar algún tipo de maloclusión provocados por los hábitos nocivos es importante identificarlos debido que pueden evolucionar y por ello es fundamental prevenirlos (Paolantonio, 2019).

De acuerdo con este resultado se pudo apreciar que la mayor incidencia tiene la succión digital, seguida del biberón, es decir que son los hábitos que pueden generar malformación dental en los niños.

Tabla 2. Hábitos orales

\begin{tabular}{|c|c|c|c|}
\hline AUTORES & AÑO & OBJETIVO & CONCLUSIONES \\
\hline $\begin{array}{l}\text { Espinoza } \\
\text { et al. }\end{array}$ & 2016 & $\begin{array}{l}\text { Evaluar la prevalencia } \\
\text { de hábitos orales y } \\
\text { alteraciones } \\
\text { dentoalveolares en } \\
\text { niños de } 6 \text { a } 12 \text { años } \\
\text { atendidos en una } \\
\text { Clínica Docente. }\end{array}$ & $\begin{array}{l}\text { Se encontró asociación entre las } \\
\text { relaciones molares derecha e izquierda } \\
\text { según Angle con la edad }(p=0.000) \text {, sin } \\
\text { embargo, con el género no se encontró } \\
\text { asociación estadísticamente significativa } \\
(p=0.430) \text {. }\end{array}$ \\
\hline $\begin{array}{l}\text { Araújo et } \\
\text { al. }\end{array}$ & 2019 & $\begin{array}{l}\text { Verificar la prevalencia } \\
\text { de maloclusión en niños } \\
\text { preescolares de un } \\
\text { municipio del suroeste } \\
\text { de Bahía, evaluando la } \\
\text { presencia de mordida } \\
\text { cruzada posterior } \\
\text { unilateral y su relación } \\
\text { con hábitos bucales } \\
\text { deletéreos. }\end{array}$ & $\begin{array}{l}\text { Fue posible verificar que la prevalencia de } \\
\text { la maloclusión en niños preescolares de } \\
\text { un municipio del suroeste de Bahía es del } \\
21,4 \% \text {, ese índice está directamente } \\
\text { relacionado con los hábitos bucales } \\
\text { deletéreos prolongados. }\end{array}$ \\
\hline $\begin{array}{l}\text { Meneses } \\
\text { et al. }\end{array}$ & 2015 & $\begin{array}{l}\text { Escribir el perfil } \\
\text { epidemiológico de la } \\
\text { oclusión dental estática } \\
\text { y algunos hábitos orales } \\
\text { de un grupo de } \\
\text { escolares de Medellín. }\end{array}$ & $\begin{array}{l}\text { El perfil epidemiológico de los escolares } \\
\text { evaluados y su oclusión estática indica } \\
\text { una baja prevalencia de alteraciones, } \\
\text { que incluye mordida en tijera, cruzada y } \\
\text { abierta. }\end{array}$ \\
\hline
\end{tabular}

Como se observa los tres estudios realizados estudian la relación de los hábitos orales con las malformaciones y maloclusiones que se presentan en los niños en edad escolar.
De los 86 niños examinados, 45 presentaron dentición temporal $(52,3$ \%) y 41 dentición mixta temprana (47,7\%) (Martínez et al, 2017). 
Tabla 3. Principales estudios de malformaciones.

\begin{tabular}{|c|c|c|c|c|}
\hline Autor/Año/Revista & País & Diseño & Sujeto & Principales resultados \\
\hline $\begin{array}{l}\text { Segura et al. } \\
2017 . \\
\text { Correo Científico } \\
\text { Médico (CCM) }\end{array}$ & Cuba & Estudio Transversal & $\begin{array}{c}715 \\
\text { niños }\end{array}$ & $\begin{array}{l}\text { La prevalencia de la } \\
\text { mordida cruzada fue de } \\
19,72 \% \text {, en el sexo } \\
\text { femenino se obtuvo el } \\
19,95 \% \text {. Las causas que } \\
\text { más contribuyeron a que } \\
\text { se produjera dicha } \\
\text { alteración fueron los } \\
\text { hábitos bucales } \\
\text { deformantes }\end{array}$ \\
\hline $\begin{array}{l}\text { Díaz et al. (2015). } \\
\text { Revista de Ciencias } \\
\text { Médicas de } \\
\text { Cienfuegos }\end{array}$ & Cuba & Estudio Transversal & $\begin{array}{c}116 \\
\text { niños }\end{array}$ & $\begin{array}{l}\text { Entre los principales } \\
\text { resultados se destacan } \\
\text { que después de la } \\
\text { intervención el } 81.8 \% \\
\text { adquirieron } \\
\text { conocimiento adecuado } \\
\text { respecto al hábito, las } \\
\text { anomalías } \\
\text { dentomaxilofaciales }\end{array}$ \\
\hline $\begin{array}{l}\text { Hernández et al. } \\
\text { (2015) } \\
\text { Revista de Ciencias } \\
\text { Médicas de Pinar del } \\
\text { Río }\end{array}$ & Cuba & Estudio Observacional & $\begin{array}{c}188 \\
\text { niños }\end{array}$ & $\begin{array}{l}\text { El } 65 \% \text { de las mordidas } \\
\text { abiertas se encontraron } \\
\text { en el sexo femenino y la } \\
\text { raza blanca, } \\
\text { disminuyendo la } \\
\text { prevalencia a medida que } \\
\text { aumenta la edad. }\end{array}$ \\
\hline $\begin{array}{l}\text { Veliz et al. (2018) } \\
\text { Revista Científico- } \\
\text { Académica } \\
\text { Multidisciplinaria }\end{array}$ & Ecuador & Estudio Transversal & $\begin{array}{c}233 \\
\text { niños }\end{array}$ & $\begin{array}{l}\text { Entre los principales } \\
\text { resultados sobresalieron } \\
\text { los hábitos deformantes } \\
\text { bucales, así como las } \\
\text { maloclusiones ligeras y } \\
\text { de la clase I de Angle. }\end{array}$ \\
\hline $\begin{array}{l}\text { Hechavarría et al. } \\
2020 \text {. } \\
\text { Revista KIRU. }\end{array}$ & Cuba & Estudio Transversal & $\begin{array}{c}57 \\
\text { niños }\end{array}$ & $\begin{array}{l}\text { Predominó el sexo } \\
\text { masculino y el periodo de } \\
\text { dentición temporal. La } \\
\text { respiración bucal y el uso } \\
\text { del biberón fueron los } \\
\text { hábitos deformantes más } \\
\text { practicados. }\end{array}$ \\
\hline $\begin{array}{l}\text { Sánchez et al. (2017) } \\
\text { Revista de Ciencias } \\
\text { Médicas de Pinar del } \\
\text { Río. }\end{array}$ & Cuba & Estudio Observacional & $\begin{array}{c}203 \\
\text { niños }\end{array}$ & $\begin{array}{l}\text { La lactancia materna } \\
\text { exclusiva representó la } \\
\text { cifra más alta con el } 64.53 \\
\% \text { y el período } \\
\text { predominante fue el } \\
\text { mayor de } 6 \text { meses, } \\
(46.7 \%) \text { seguida de la } \\
\text { materna no exclusiva o } \\
\text { mixta } 25.12 \% \text {. }\end{array}$ \\
\hline $\begin{array}{l}\text { García et al. (2014) } \\
\text { Avances en } \\
\text { Odontoestomatología }\end{array}$ & España & Estudio Observacional & $\begin{array}{l}1051 \\
\text { niños }\end{array}$ & $\begin{array}{l}\text { El } 72,8 \% \text { presenta según } \\
\text { Angle Clase I, } 19,0 \% \text { y } \\
5,2 \% \text { Clase II/1 y II/2 } \\
\text { respectivamente y } 2,9 \% \\
\text { Clase III. El hábito } \\
\text { onicofagia fue el más } \\
\text { frecuente con un } 46,4 \% .\end{array}$ \\
\hline $\begin{array}{l}\text { Cisneros y Cruz. } \\
2017 . \\
\text { Medisan. }\end{array}$ & Cuba & Estudio Transversal & $\begin{array}{c}60 \\
\text { niños }\end{array}$ & $\begin{array}{l}\text { En la serie predominaron } \\
\text { los niños de } 4 \text { años de } \\
\text { edad, el sexo femenino y } \\
\text { las maloclusiones; en } \\
\text { tanto, la succión digital y } \\
\text { la disfunción lingual } \\
\text { fueron los hábitos } \\
\text { fundamentales. }\end{array}$ \\
\hline
\end{tabular}




\begin{tabular}{|c|c|c|c|c|}
\hline $\begin{array}{l}\text { Arocha et al. } \\
2016 . \\
\text { Medisan. }\end{array}$ & Cuba & Estudio Transversal & $\begin{array}{c}150 \\
\text { niños }\end{array}$ & $\begin{array}{l}\text { Se concluye que el sexo } \\
\text { masculino }(52,0 \%) \text {, las } \\
\text { maloclusiones en este } \\
\text { mismo sexo }(59,3 \%) \text { y el } \\
\text { uso del biberón como } \\
\text { hábito deformante }(41,1 \\
\%) \text {. }\end{array}$ \\
\hline $\begin{array}{l}\text { Mesa y Medrano. } \\
2017 . \\
\text { CCM. }\end{array}$ & Cuba & Estudio Transversal & $\begin{array}{c}132 \\
\text { niños }\end{array}$ & $\begin{array}{l}\text { El hábito bucal } \\
\text { deformante detectado } \\
\text { con mayor frecuencia } \\
\text { resultó el chupeteo de } \\
\text { tete y biberón }(69,69 \%) \text {, } \\
\text { seguido del empuje } \\
\text { lingual (62,87\%) y la } \\
\text { succión del pulgar u otros } \\
\text { dedos (45,45\%). }\end{array}$ \\
\hline $\begin{array}{l}\text { Rodríguez et al. } \\
2017 . \\
\text { Crea Ciencia Revista } \\
\text { Científica. }\end{array}$ & $\begin{array}{c}\text { El } \\
\text { Salvador }\end{array}$ & Estudio observacional & $\begin{array}{c}30 \\
\text { sujetos }\end{array}$ & $\begin{array}{l}\text { Los hábitos bucales } \\
\text { deformantes más } \\
\text { frecuentes fueron, la } \\
\text { succión digital } 69 \text { niños y } \\
\text { la onicofagia en siete } \\
\text { niños predominando } \\
\text { ambos en el sexo } \\
\text { femenino }\end{array}$ \\
\hline $\begin{array}{l}\text { Rondón et al. } \\
2021 . \\
\text { Revista de } \\
\text { Odontopediatría } \\
\text { Latinoamericana }\end{array}$ & Venezuela & Estudio Transversal & $\begin{array}{c}183 \\
\text { niños }\end{array}$ & $\begin{array}{l}\text { El género femenino } \\
\text { ocupó un } 56,3 \% \text {, el } \\
\text { promedio de edad fue de } \\
8,4 \pm 1,29 \text { años. }\end{array}$ \\
\hline $\begin{array}{l}\text { Arias et al. } \\
2019 . \\
\text { Revista Odontológica } \\
\text { Basadrina. }\end{array}$ & Perú & Estudio Transversal & $\begin{array}{c}140 \\
\text { niños }\end{array}$ & $\begin{array}{l}\text { Dentro de los hábitos no } \\
\text { fisiológicos, se observó la } \\
\text { respiración naso bucal } \\
\text { presente en un } 12.1 \% \text {; la } \\
\text { succión digital, en un } \\
7.9 \% \text {; la succión labial, } \\
\text { con } 0.7 \% \text {; la onicofagia, } \\
\text { con } 17.9 \% \text {; la deglución } \\
\text { atípica, con } 2.1 \% \text {. }\end{array}$ \\
\hline $\begin{array}{l}\text { Mendoza et al. (2017). } \\
\text { Revista Científica } \\
\text { Dominio de las } \\
\text { Ciencias. }\end{array}$ & Ecuador & Estudio Observacional & $\begin{array}{c}202 \\
\text { sujetos }\end{array}$ & $\begin{array}{l}\text { Los resultados indican } \\
\text { una relación entre el } \\
\text { tiempo } \\
\text { amamantamiento menor } \\
\text { a } 6 \text { meses y el desarrollo } \\
\text { de hábitos deformantes. }\end{array}$ \\
\hline $\begin{array}{l}\text { Serrano et al. } \\
2019 . \\
\text { CCM. }\end{array}$ & Cuba & Estudio Transversal & $\begin{array}{c}126 \\
\text { sujetos }\end{array}$ & $\begin{array}{l}\text { El nivel de conocimiento } \\
\text { sobre salud bucal fue } \\
\text { regular en el sexo } \\
\text { femenino, en el } 71,6 \% \text {, y } \\
\text { en el masculino fue malo, } \\
\text { en el } 46,7 \%\end{array}$ \\
\hline $\begin{array}{l}\text { Torres et al. } \\
2017 . \\
\text { CCM. }\end{array}$ & Cuba & Estudio Transversal & $\begin{array}{c}236 \\
\text { niños }\end{array}$ & $\begin{array}{l}\text { El } 19,9 \% \text {. Predominó el } \\
\text { sexo masculino }(68,1 \%) \\
\text { en escolares con lesión } \\
\text { traumática. El hábito } \\
\text { bucal deformante más } \\
\text { frecuente fue la succión } \\
\text { digital en el } 82,9 \% \text {. }\end{array}$ \\
\hline $\begin{array}{l}\text { Pérez. (2021). } \\
\text { Revista Científico- } \\
\text { Académica } \\
\text { Multidisciplinaria. }\end{array}$ & Ecuador & Estudio Observacional & $\begin{array}{c}185 \\
\text { sujetos }\end{array}$ & $\begin{array}{l}\text { La maloclusión de mayor } \\
\text { significación fue la } \\
\text { mordida abierta anterior } \\
31.9 \% \text {. Hubo predominio } \\
\text { respiración bucal } 32.4 \% \text { y } \\
\text { lengua protráctil } 30.8 \% \\
\text { fueron los hábitos } \\
\text { deformantes de mayor } \\
\text { significación. }\end{array}$ \\
\hline
\end{tabular}




\begin{tabular}{|c|c|c|c|c|}
\hline $\begin{array}{l}\text { Salamanca y Murrieta. } \\
2015 . \\
\text { Revista Científica } \\
\text { Odontológica. }\end{array}$ & $\begin{array}{c}\text { Costa } \\
\text { Rica }\end{array}$ & Estudio Observacional & $\begin{array}{c}303 \\
\text { niños }\end{array}$ & $\begin{array}{l}\text { El } 22,9 \% \text { de los niños } \\
\text { presentó alguna } \\
\text { alteración en la oclusión, } \\
\text { siendo más frecuente la } \\
\text { mordida abierta y el } \\
42,4 \% \text { presentó por lo } \\
\text { menos algún tipo de } \\
\text { habito bucal. }\end{array}$ \\
\hline $\begin{array}{l}\text { Mendoza et al. } \\
2019 . \\
\text { Memorias del Instituto } \\
\text { de Investigaciones en } \\
\text { Ciencias de la Salud. }\end{array}$ & Paraguay & Estudio Observacional & $\begin{array}{c}344 \\
\text { niños }\end{array}$ & $\begin{array}{l}\text { El } 13,08 \%(45) \text { realizaba } \\
\text { succión digital, el } 9,59 \% \\
\text { (33) succión de chupete y } \\
\text { el } 38,95 \% \quad(134) \text { otros } \\
\text { hábitos. }\end{array}$ \\
\hline $\begin{array}{l}\text { Fernández, P. } \\
2020 . \\
\text { Pediatría integral. }\end{array}$ & España & Estudio Observacional & $\begin{array}{l}29195 \\
\text { sujetos }\end{array}$ & $\begin{array}{l}\text { La valoración de la } \\
\text { lactancia materna debe } \\
\text { llevarse a cabo cuanto } \\
\text { antes; si es posible, en } \\
\text { las primeras } 24-48 \text { horas } \\
\text { tras el alta hospitalaria, } \\
\text { para comprobar un buen } \\
\text { comienzo de la misma. }\end{array}$ \\
\hline $\begin{array}{l}\text { González et al. } \\
2019 . \\
\text { Revista Archivo } \\
\text { Médico de Camagüey }\end{array}$ & Cuba & Estudio Transversal & $\begin{array}{c}100 \\
\text { sujetos }\end{array}$ & $\begin{array}{l}\text { Relacionado } \text { con los } \\
\text { conocimientos } \\
\text { lactancia } \\
\text { sobre } \\
\text { posterior a la intervención } \\
\text { educativa el } 94 \% \text { de las } \\
\text { gestantes obtuvieron } \\
\text { resultados de bien, } 21,3 \\
\% \text { contaba con } 36 \text { y más } \\
\text { años de edad y } 69,6 \% \\
\text { nivel escolar universitario }\end{array}$ \\
\hline $\begin{array}{l}\text { Solís, M. } \\
2018 . \\
\text { Revista Odontología } \\
\text { Pediátrica. }\end{array}$ & Perú & Estudio Observacional & $\begin{array}{c}113 \\
\text { sujetos }\end{array}$ & $\begin{array}{l}\text { Sólo el } 79 \% \text { de pediatras } \\
\text { y el } 68 \% \text { de odontólogos } \\
\text { sospecha de la presencia } \\
\text { de un hábito de succión al } \\
\text { observar la presencia de } \\
\text { ciertas características. }\end{array}$ \\
\hline $\begin{array}{l}\text { Lima et al. } \\
2019 . \\
\text { Revista Cubana de } \\
\text { Estomatología }\end{array}$ & Cuba & Estudio observacional & $\begin{array}{c}65 \\
\text { sujetos }\end{array}$ & $\begin{array}{l}\text { El } 89,5 \% \text { de los artículos } \\
\text { pertenecen a estudios de } \\
\text { hábitos de succión no } \\
\text { nutritivos solo o en } \\
\text { conjunto con otros } \\
\text { hábitos; y el } 10,5 \% \\
\text { realizan investigaciones } \\
\text { en niños respiradores } \\
\text { bucales. }\end{array}$ \\
\hline $\begin{array}{l}\text { Puga et al. } \\
2015 . \\
\text { Revista Electrónica de } \\
\text { Portales Médicos. }\end{array}$ & España & Estudio Observacional & $\begin{array}{c}200 \\
\text { sujetos }\end{array}$ & $\begin{array}{l}\text { Un } 80 \% \text { de las madres } \\
\text { eligen dar el pecho a sus } \\
\text { hijos en el momento del } \\
\text { nacimiento, } \\
\text { disminuyendo a un } 56 \% \\
\text { la proporción de bebés } \\
\text { alimentados } \\
\text { exclusivamente con leche } \\
\text { materna a los tres meses } \\
\text { de nacer y a un } 21 \% \text { a los } \\
\text { seis meses. }\end{array}$ \\
\hline $\begin{array}{l}\text { Aguilar et al. (2018) } \\
\text { Boletín médico del } \\
\text { Hospital Infantil de } \\
\text { México }\end{array}$ & México & Estudio Observacional & $\begin{array}{c}640 \\
\text { niños }\end{array}$ & $\begin{array}{l}\text { El tratamiento de } \\
\text { rehabilitación consiste en } \\
\text { el posicionamiento del } \\
\text { niño y el cuidador al } \\
\text { momento de la } \\
\text { alimentación, } \\
\text { regulación la de la } \\
\text { sensibilidad y el tono } \\
\text { muscular perioral e } \\
\text { intraoral, }\end{array}$ \\
\hline
\end{tabular}




\begin{tabular}{|c|c|c|c|c|}
\hline $\begin{array}{l}\text { Álvarez et al. } \\
2016 . \\
\text { Revista Electrónica } \\
\text { Dr. Zoilo E. Marinello } \\
\text { Vidaurreta. }\end{array}$ & Cuba & Estudio Observacional & $\begin{array}{c}325 \\
\text { niños }\end{array}$ & $\begin{array}{l}\text { La práctica de hábitos } \\
\text { deformantes fue elevada } \\
\text { entre los escolares, } \\
\text { siendo superior en el } \\
\text { sexo femenino. La } \\
\text { deglución atípica y la } \\
\text { onicofagia fueron los } \\
\text { hábitos practicados con } \\
\text { mayor frecuencia }\end{array}$ \\
\hline $\begin{array}{l}\text { Araújo et al. (2019) } \\
\text { Revista de } \\
\text { Odontopediatría } \\
\text { Latinoamericana }\end{array}$ & Brasil & Estudio Transversal & $\begin{array}{c}440 \\
\text { niños }\end{array}$ & $\begin{array}{l}\text { Se encontró un } \\
\text { porcentaje de } 94,28 \% \text { de } \\
\text { los casos con mordida } \\
\text { cruzada posterior } \\
\text { unilateral relacionada a } \\
\text { hábitos bucales. }\end{array}$ \\
\hline $\begin{array}{l}\text { Arias et al. } \\
2016 . \\
\text { Revista Nacional de } \\
\text { Odontología }\end{array}$ & Colombia & Estudio Transversal & $\begin{array}{c}598 \\
\text { niños }\end{array}$ & $\begin{array}{l}\text { La deglución atípica y la } \\
\text { mordida abierta están } \\
\text { directamente } \\
\text { relacionadas, lo cual } \\
\text { sugiere que la función } \\
\text { deglutiva puede ser un } \\
\text { factor causal de } \\
\text { maloclusión; igualmente, } \\
\text { se encontró una relación } \\
\text { directa entre succión } \\
\text { digital y mordida cruzada } \\
\text { posterior. }\end{array}$ \\
\hline $\begin{array}{l}\text { Borrie et al. } \\
2015 . \\
\text { Cochrane. }\end{array}$ & Cuba & Estudio Transversal & $\begin{array}{l}252 \\
\text { niños }\end{array}$ & $\begin{array}{l}\text { La succión del dedo fue el } \\
\text { único HSNN evaluado en } \\
\text { los estudios. Cinco } \\
\text { estudios compararon } \\
\text { intervenciones únicas o } \\
\text { múltiples con ninguna } \\
\text { intervención. }\end{array}$ \\
\hline $\begin{array}{l}\text { Brahm y Valdés. } \\
\text { 2017. } \\
\text { Revista Chilena de } \\
\text { Pediatría }\end{array}$ & Chile & Estudio Observacional & $\begin{array}{c}750 \\
\text { niños }\end{array}$ & $\begin{array}{l}\text { La LM puede prevenir un } \\
13 \% \text { de la mortalidad } \\
\text { infantil en el mundo, y } \\
\text { disminuye el riesgo de } \\
\text { muerte súbita del lactante } \\
\text { en un } 36 \% \text {. }\end{array}$ \\
\hline $\begin{array}{l}\text { Carrillo et al. } \\
2016 . \\
\text { Dialnet. }\end{array}$ & Ecuador & Estudio Observacional & $\begin{array}{c}435 \\
\text { niños }\end{array}$ & $\begin{array}{l}\text { La prevalencia del HSNN } \\
\text { fue del } 52.6 \% \text {, la } \\
\text { prevalencia } \\
\text { maloclusión } 38.6 \% \text {, el } \\
\text { tipo de HSNN más } \\
\text { frecuente fue la succión } \\
\text { digital con } 21.6 \% \text {. }\end{array}$ \\
\hline $\begin{array}{l}\text { Carvajal et al. } \\
2015 . \\
\text { ECORFAN. }\end{array}$ & Bolivia & Estudio Transversal & $\begin{array}{c}263 \\
\text { niños }\end{array}$ & $\begin{array}{l}\text { El } 39 \% \text { de la población } \\
\text { estudiada presentó, al } \\
\text { menos, un Hábito Bucal. } \\
\text { El grupo etéreo donde se } \\
\text { encontró un elevado } \\
\text { número de casos con } \\
\text { algún tipo de Hábitos. }\end{array}$ \\
\hline $\begin{array}{l}\text { Chung et al. } \\
2018 . \\
\text { Odontología } \\
\text { Pediátrica. }\end{array}$ & España & Estudio Transversal & $\begin{array}{c}43 \\
\text { sujetos }\end{array}$ & $\begin{array}{l}\text { Es importante destacar la } \\
\text { importancia de la } \\
\text { prevención y el } \\
\text { tratamiento precoz de la } \\
\text { disrupción del hábito a } \\
\text { través de un abordaje } \\
\text { multidisciplinario }\end{array}$ \\
\hline $\begin{array}{l}\text { Crespo et al. (2020). } \\
\text { KILLKANA. }\end{array}$ & Ecuador & Estudio Observacional & $\begin{array}{c}185 \\
\text { niños }\end{array}$ & $\begin{array}{l}\text { Los resultados mostraron } \\
\text { que el } 77 \% \text { de la muestra } \\
\text { consistió en escolares } \\
\text { masculinos y el } 78 \% \\
\text { femenino. }\end{array}$ \\
\hline
\end{tabular}




\begin{tabular}{|c|c|c|c|c|}
\hline $\begin{array}{l}\text { Dickmar et al. (2015). } \\
\text { Revista De } \\
\text { Odontopediatría } \\
\text { Latinoamericana }\end{array}$ & Venezuela & $\begin{array}{c}\text { Estudio } \\
\text { Transversal/Observacional }\end{array}$ & $\begin{array}{l}37 \\
\text { niños }\end{array}$ & $\begin{array}{l}\text { Se observó que } \\
\text { aquellos pacientes que } \\
\text { fueron amamantados por } \\
\text { un periodo mayor a } 6 \\
\text { meses presentaron } \\
\text { menos enfermedades } \\
\text { alérgicas }\end{array}$ \\
\hline $\begin{array}{l}\text { Espinoza et al. } \\
2016 . \\
\text { Revista Odontología } \\
\text { Pediátrica. }\end{array}$ & & Estudio Transversal & $\begin{array}{c}1006 \\
\text { sujetos }\end{array}$ & $\begin{array}{l}\text { Manifestándose una } \\
\text { predisposición al hábito } \\
\text { de deglución atípica } \\
(19,48 \%) ; \text { succión digital } \\
(2.19 \%) \text { y respiración } \\
\text { bucal (0.20\%). La } \\
\text { prevalencia de las } \\
\text { alteraciones } \\
\text { dentoalveolares mordida } \\
\text { cruzada anterior (8.65\%) } \\
\text { y posterior }(5.27 \%)\end{array}$ \\
\hline $\begin{array}{l}\text { Gálvez et al. } \\
2017 . \\
\text { Medicentro } \\
\text { Electrónica. }\end{array}$ & Cuba & Estudio Observacional & $\begin{array}{l}100 \\
\text { sujetos }\end{array}$ & $\begin{array}{l}\text { Los hábitos bucales } \\
\text { deformantes son causas } \\
\text { frecuentes de } \\
\text { maloclusiones, se } \\
\text { instalan en el } 56 \% \text { al } 75 \% \\
\text { de los niños entre tres y } \\
\text { cinco años, aparecen } \\
\text { solos o combinados }\end{array}$ \\
\hline $\begin{array}{l}\text { González. (2018). } \\
\text { Revista Médica } \\
\text { Multimed. }\end{array}$ & Cuba & Estudio Transversal & $\begin{array}{c}676 \\
\text { niños }\end{array}$ & $\begin{array}{l}\text { Entre los principales } \\
\text { resultados sobresalió una } \\
\text { alta prevalencia }(64,6 \%) \\
\text { de las anomalías de la } \\
\text { atención primaria en los } \\
\text { niños estudiados, }\end{array}$ \\
\hline $\begin{array}{l}\text { Herrero y Arias. } \\
\text { (2019). } \\
\text { Multimed. }\end{array}$ & Cuba & Estudio Observacional & $\begin{array}{l}100 \\
\text { sujetos }\end{array}$ & $\begin{array}{l}\text { Los hábitos bucales } \\
\text { deformantes son factores } \\
\text { etiológicos en la aparición } \\
\text { de maloclusiones, } \\
\text { alterando el normal } \\
\text { crecimiento del individuo } \\
\text { y ocasionando un } \\
\text { desequilibrio funcional } \\
\text { del sistema } \\
\text { estomatognático. }\end{array}$ \\
\hline $\begin{array}{l}\text { Iglesias et al. } \\
2016 . \\
\text { Universidad Médica } \\
\text { Pinareña }\end{array}$ & Cuba & Estudio Observacional & $\begin{array}{c}150 \\
\text { sujetos }\end{array}$ & $\begin{array}{l}\text { El } 62,0 \% \text { de los pacientes } \\
\text { pertenecieron al sexo } \\
\text { femenino y al grupo de } \\
\text { edad de } 10 \text { a } 14 \text { años. La } \\
\text { anomalía oclusal más } \\
\text { frecuente fue el resalte } \\
\text { aumentado, hallado en el } \\
48,0 \% \text { de la población. }\end{array}$ \\
\hline $\begin{array}{l}\text { Letini et al. } \\
2015 . \\
\text { Cochrane. }\end{array}$ & Cuba & Estudio Observacional & $\begin{array}{l}60 \\
\text { sujetos }\end{array}$ & $\begin{array}{l}\text { El RF-4 asociado con el } \\
\text { entrenamiento de sellado } \\
\text { labial (RR } 0,02 \text { [IC del } \\
95 \%: 0,00 \text { a } 0,38] \text { y la } \\
\text { rejilla palatina extraíble } \\
\text { asociada con la } \\
\text { mentonera de tracción } \\
\text { occipital (RR } 0,23[\text { [IC del } \\
95 \%: 0,11 \text { a 0,48]) } \\
\text { pudieron corregir la } \\
\text { mordida abierta anterior. }\end{array}$ \\
\hline $\begin{array}{l}\text { Armas et al. (2020). } \\
\text { Revista } \\
\text { Latinoamericana de } \\
\text { Ortodoncia y } \\
\text { Odontopediatría }\end{array}$ & Venezuela & Estudio Transversal & $\begin{array}{c}17 \\
\text { sujetos }\end{array}$ & $\begin{array}{l}\text { Los factores de riesgo } \\
\text { maternos y neonatales; } \\
\text { mal estado nutricional de } \\
\text { la madre, ganancia } \\
\text { inadecuada de peso de la }\end{array}$ \\
\hline
\end{tabular}




\begin{tabular}{|c|c|c|c|c|}
\hline & & & & $\begin{array}{l}\text { madre, lactancia materna } \\
\text { inadecuada }\end{array}$ \\
\hline $\begin{array}{l}\text { López et al. } \\
2016 . \\
\text { Universitas } \\
\text { Odontológica }\end{array}$ & Colombia & Estudio Observacional & $\begin{array}{l}18 \\
\text { sujetos }\end{array}$ & $\begin{array}{l}\text { La aparición de hábitos } \\
\text { parafuncionales está } \\
\text { relacionada con periodos } \\
30 \text { cortos de lactancia } \\
\text { materna (menor a } 6 \\
\text { meses). }\end{array}$ \\
\hline $\begin{array}{l}\text { Lópes. } \\
2017 . \\
\text { Universidad de } \\
\text { Barcelona. }\end{array}$ & España & Estudio Transversal & $\begin{array}{c}275 \\
\text { niños }\end{array}$ & $\begin{array}{l}\text { Los resultados } \\
\text { demostraron que existió } \\
\text { una relación significativa } \\
\text { entre el uso del chupete, } \\
\text { alteraciones en la } \\
\text { relación transversal (OR= } \\
3.29 ; \text { IC95\%: } 0.97-11.17 \text {, } \\
\text { p=0.044) y desviación de } \\
\text { la línea media. }\end{array}$ \\
\hline $\begin{array}{l}\text { Martínez. } \\
2017 . \\
\text { MEDISAN. }\end{array}$ & Cuba & Estudio Observacional & $\begin{array}{c}86 \\
\text { niños }\end{array}$ & $\begin{array}{l}\text { En la serie se obtuvo que } \\
\text { al menos } 17,4 \% \text { de los } \\
\text { niños examinados } \\
\text { presentaban alteración } \\
\text { en la oclusión } \\
\text { permanente respecto a la } \\
\text { relación de los molares } \\
\text { temporales }\end{array}$ \\
\hline $\begin{array}{l}\text { Mena y Sánchez. } \\
2019 . \\
\text { Repositorio de la } \\
\text { Universidad Jaume I }\end{array}$ & España & Estudio Observacional & $\begin{array}{l}1897 \\
\text { sujetos }\end{array}$ & $\begin{array}{l}\text { Se obtuvieron } 1897 \\
\text { artículos; el } 2.3 \%(n=44) \\
\text { fue incluido. De estos, el } \\
6.8 \%(n=3) \text { trata temas } \\
\text { relacionados con el } \\
\text { cuidado del chupete; y el } \\
93.2 \%(n=41) \text { restante, } \\
\text { sobre efectos derivados } \\
\text { de su uso. }\end{array}$ \\
\hline $\begin{array}{l}\text { Méndez et al. } \\
2017 . \\
\text { Correo Científico } \\
\text { Médico }\end{array}$ & Cuba & Estudio Transversal & $\begin{array}{c}180 \\
\text { niños }\end{array}$ & $\begin{array}{l}\text { Hubo predominio de } \\
\text { niños con hábitos bucales } \\
\text { deformantes en el sexo } \\
\text { femenino }(57,2 \%) \text { y en la } \\
\text { edad de } 10 \text { años }(37,2 \%) \text {, } \\
\text { predominó como hábito } \\
\text { deformante la lengua } \\
\text { protráctil }(39,2 \%)\end{array}$ \\
\hline $\begin{array}{l}\text { Meneses et al. (2015). } \\
\text { Revista Nacional } \\
\text { Odontológica }\end{array}$ & Colombia & Estudio Transversal & $\begin{array}{c}420 \\
\text { niños }\end{array}$ & $\begin{array}{l}\text { la edad promedio fue de } \\
8,7 \text { años }( \pm 1,8) ; \text { el } 50,2 \% \\
(211) \text { eran mujeres; el } \\
26,4 \%(111) \text { y el } 24,5 \% \\
(103) \quad \text { presentaron } \\
\text { relación canina clase i } \\
\text { derecha e izquierda }\end{array}$ \\
\hline $\begin{array}{l}\text { Mora et al. } \\
2017 . \\
\text { Revista Nacional } \\
\text { Odontológica }\end{array}$ & Cuba & Estudio Transversal & $\begin{array}{l}1238 \\
\text { niños }\end{array}$ & \begin{tabular}{llr}
$\begin{array}{l}\text { Se erradicó el } \\
\text { los hábitos }\end{array}$ & deformantes \\
(más & frecuentes \\
protracción & \multicolumn{2}{c}{ lingual, } \\
succión de & biberón y \\
onicofagia) y & hubo \\
reducción de & las \\
anomalías & & \\
dentomaxilofaciales & \\
\end{tabular} \\
\hline $\begin{array}{l}\text { Morera et al. } \\
2016 . \\
\text { MediSur }\end{array}$ & Cuba & Estudio Transversal & $\begin{array}{c}67 \\
\text { niños }\end{array}$ & $\begin{array}{l}\text { Se elevó el nivel de } \\
\text { conocimientos de niños y } \\
\text { padres acerca de factores } \\
\text { de riesgo asociados a } \\
\text { maloclusión. Se erradicó } \\
\text { el } 94,3 \% \text { de los hábitos } \\
\text { deformantes } \\
\text { frecuentes más }\end{array}$ \\
\hline
\end{tabular}




\begin{tabular}{|c|c|c|c|c|}
\hline & & & & $\begin{array}{l}\text { lingual, succión digital y } \\
\text { biberón). }\end{array}$ \\
\hline $\begin{array}{l}\text { Moscardini et al. } \\
2017 . \\
\text { Revista de } \\
\text { Odontopediatría }\end{array}$ & Brasil & Estudio Observacional & $\begin{array}{l}20 \\
\text { sujetos }\end{array}$ & $\begin{array}{l}\text { El tratamiento } \\
\text { odontológico del infante } \\
\text { brinda la posibilidad de } \\
\text { mantener la salud, } \\
\text { prevenir la enfermedad y } \\
\text { representa una buena } \\
\text { práctica de promoción de } \\
\text { la salud }\end{array}$ \\
\hline $\begin{array}{l}\text { Muller y Piñeiro. } \\
\text { (2015). } \\
\text { Revista Médica } \\
\text { Clínica Las Condes }\end{array}$ & Cuba & Estudio Observacional & $\begin{array}{c}25 \\
\text { sujetos }\end{array}$ & $\begin{array}{l}\text { La presencia de malos } \\
\text { hábitos orales en } \\
\text { pacientes en crecimiento } \\
\text { puede llevar a establecer } \\
\text { o agravar la presencia de } \\
\text { anomalías } \\
\text { dentomaxilares }\end{array}$ \\
\hline $\begin{array}{l}\text { Nieto et al. (2017). } \\
\text { Educación y Salud } \\
\text { Boletín Científico } \\
\text { Instituto De Ciencias } \\
\text { de la Salud } \\
\text { Universidad } \\
\text { Autónoma Del Estado } \\
\text { De Hidalgo }\end{array}$ & México & Estudio Observacional & $\begin{array}{c}155 \\
\text { sujetos }\end{array}$ & $\begin{array}{l}\text { Como conclusión se } \\
\text { plantea que la } \\
\text { alimentación a través del } \\
\text { seno materno favorece el } \\
\text { crecimiento y desarrollo } \\
\text { del aparato masticatorio, } \\
\text { contribuye a la } \\
\text { maduración de la } \\
\text { respiración y deglución, } \\
\text { evita la adquisición de } \\
\text { hábitos deformantes } \\
\text { bucales }\end{array}$ \\
\hline $\begin{array}{l}\text { Nuñez et al. } \\
2015 .\end{array}$ & Cuba & Estudio Transversal & $\begin{array}{c}133 \\
\text { niños }\end{array}$ & $\begin{array}{l}\text { El } 78.18 \% \text { de los niños } \\
\text { estudiados presentan } \\
\text { alguno de los hábitos } \\
\text { bucales deformantes, los } \\
\text { niños de nueve años } \\
\text { representaron el } 51.87 \% \\
\text { y el } 54.88 \% \text { corresponde } \\
\text { al sexo femenino }\end{array}$ \\
\hline $\begin{array}{l}\text { Ochando. } \\
2019 . \\
\text { Barrutia }\end{array}$ & España & Estudio Transversal & $\begin{array}{c}18 \\
\text { niños }\end{array}$ & $\begin{array}{l}\text { Muchas investigaciones } \\
\text { han comprobado que la } \\
\text { succión de dedo, biberón } \\
\text { o chupete, puede ser la } \\
\text { causante de } \\
\text { malformaciones de } \\
\text { dentoesqueletales. }\end{array}$ \\
\hline $\begin{array}{l}\text { Osorio y Mora. } \\
2019 . \\
\text { Revista Científica } \\
\text { "Especialidades } \\
\text { Odontológicas UG" } \\
\end{array}$ & Ecuador & Estudio Observacional & $\begin{array}{l}100 \\
\text { sujetos }\end{array}$ & $\begin{array}{l}\text { Los efectos de la succión } \\
\text { digital excesiva } \\
\text { comprenden alteraciones } \\
\text { dentofaciales tales como } \\
\text { mordida abierta anterior }\end{array}$ \\
\hline $\begin{array}{l}\text { y Chollopetz. } \\
2015 . \\
\text { Revista Brasileira de } \\
\text { Enfermagem }\end{array}$ & Brasil & Estudio Observacional & $\begin{array}{c}100 \\
\text { niños }\end{array}$ & $\begin{array}{lr}\text { Una variedad de } & \text { de } \\
\text { intervenciones } & \text { no } \\
\text { farmacológicas } & \text { se } \\
\text { muestra efectiva, } & \text { presentando bajo riesgo } \\
\text { para los neonatos y bajo } \\
\text { costo operacional }\end{array}$ \\
\hline $\begin{array}{l}\text { Polanco et al. } \\
2019 .\end{array}$ & Cuba & Estudio Transversal & $\begin{array}{c}112 \\
\text { niños }\end{array}$ & $\begin{array}{l}\text { El nivel de conocimiento } \\
\text { fue inadecuado: } 67,85 \% \\
\text { en escolares y } 81,25 \% \\
\text { en padres, relacionado } \\
\text { con las necesidades de } \\
\text { aprendizaje sobre los } \\
\text { hábitos }\end{array}$ \\
\hline
\end{tabular}




\section{Estructura de la discusión}

\subsection{Declaración de resultados}

Los artículos analizados reflejaron que el $71,9 \%$ de la población infantil presentó el mal hábito de la succión digital, el 17\% manifestó la práctica nociva de succión de biberón, mientras que, en menor frecuencia, el $11,1 \%$ demostró una manía de succión de chupón, que afecta de igual magnitud. La malformación más frecuente producida por los hábitos de succión no nutritiva es la mordida abierta anterior.

\subsection{Fortalezas y debilidades del manuscrito}

En los últimos años se han realizado estudios prácticos que permiten tener una visión de informar sobre el presente tema; sin embargo, muchas investigaciones por general datan de años antiguos que no pueden ser tomados en consideración por lo establecido en la metodología. Se espera que en el futuro se pueda indagar un poco más sobre el tema expuesto que genera mucho interés.

\subsection{Discusión}

El objetivo de esta investigación fue identificar hábitos de succión no nutritiva que producen malformaciones dentales en niños, y en base a los artículos analizados, la población infantil presentó el mal hábito de la succión digital, la práctica nociva de succión de biberón y manía de succión de chupón.

Los resultados de la primera tabla no concuerdan con la investigación realizada por (Mallqui, J. 2018), donde manifiesta que el hábito oral más prevalente fue la deglución atípica con presión de la lengua $(23.8 \%)$, mientras que el resultado de nuestra investigación indica que el hábito oral más frecuente es el mal hábito de la succión digital (71,9\%).

Sin embargo, nuestro estudio refleja que el hábito más frecuente relacionado a las malformaciones es la succión digital, aunque según Mesa y Medrano (2017) "El hábito bucal deformante detectado con mayor frecuencia resultó el chupeteo de tete y biberón" resultados que no concuerdan con este estudio.

Los resultados de nuestra investigación manifiesta que la mordida abierta anterior es la malformación más relevante, dato que concuerda con el estudio en el que se expresa que "La maloclusión 
de mayor significación fue la mordida abierta anterior". (Pérez, 2021)

\section{Conclusiones}

Se tiene como conclusión que la lactancia materna es fundamental, siendo un estimulante en el crecimiento y desarrollo de los niños. La mayoría de las madres utilizan con los niños objeto de entretención, los cuales pueden llegar a afectar a la dentición y musculatura peribucal. Además, se debe tomar en cuenta que la alimentación por medio del biberón influye de igual manera. Estos problemas, provocan malformaciones como mordida abierta anterior, sobrepase aumentado, mordida cruzada posterior, paladar profundo, entre otros. Es necesario que los padres tengan un papel fundamental durante los primeros 5 años de vida del infante, porque es en esta etapa donde tienden a adquirir rápidamente hábitos de succión no nutritiva.

\section{Recomendaciones}

Se plantea la creación de programas de capacitación para las madres lactantes, seguido de la capacitación en las escuelas en inicial, de esta forma erradicar de raíz los malos hábitos no nutritivos que tienen los infantes.

\section{Bibliografía}

Aguilar, E., Pérez, M., Martín, M., Romero, A. (2018) Rehabilitación de las alteraciones en la succión y deglución en recién nacidos prematuros de la unidad de cuidados intensivos neonatales. Boletín médico del Hospital Infantil de México. (Vol.

75) http://www.scielo.org.mx/sciel o.php?script=sci_arttext\&pid= S1665-11462018000100015

Álvarez, Y., González, Y., Ureña, M., Rodríguez, Y. (2016). Prevalencia de hábitos deformantes bucales en escolares de seis a nueve años. (Vol. 41). Revista Electrónica.

http://www.revzoilomarinello.s Id.cu/index.php/zmv/article/vi ew/843/pdf_316

Araújo, A., Coelho, P., Tavares, M., Flávia, A., Morais, L. (2019). Relación entre mordida cruzada posterior unilateral y hábitos bucales deletéreos en preescolares de un municipio del sudoeste del Bahía. Revista De Odontopediatría Latinoamericana, $9(1), 9$. https://www.revistaodontoped iatria.org/index.php/alop/articl e/view/165/49 
Arias, A., Espinal, G., Ponce, M., Posada, S., Nava, J., Salcedo, B. (2016). Frecuencia de hábitos orales relacionados con la maloclusión en pacientes de 4 a 12 años: estudio comparativo entre San Luis PotosíMéxico y Medellín-Colombia.

Universidad Cooperativa de Colombia.

http://dx.doi.org/10.16925/od. v13i26.1814

Arias, G., Ayca, I., Martínez, N., Condori, W. (2019). Prevalencia de hábitos bucales no fisiológicos y su relación con las maloclusiones dentarias en niños de 3 a 5 años de la I.E. Inicial Nuestros Héroes de la Guerra del Pacífico Tacna2016. Revista Odontológica Basadrina, 3(1), 20-24. https://doi.org/10.33326/2664 4649.2019.3.1.821

Armas, L., Acosta, A., Torre, Y. (2020). Influencias nutricionales en el brote de los dientes temporales. https://www.ortodoncia.ws/pu blicaciones/2020/art-32/

Arocha, A. Aranda, M. S. Pérez, Y., Granados, Hormigó, A. E. (2016). Maloclusiones y hábitos bucales deformantes en escolares con dentición mixta temprana. MEDISAN, vol. 20, núm. 4, 2016, pp. 426432.

https://www.redalyc.org/articu lo.oa? id=368445189002
Borrie, F., Bearn, D., Zipporah, I. (2015). Intervenciones para la interrupción de los hábitos de succión no nutritivos en los niños. Cochrane Database of Systematic Reviews. https://www.cochranelibrary.c om/es/cdsr/doi/10.1002/1465 1858.CD008694.pub2/full/es

Brahm, P., y Valdés, V. (2017). Beneficios de la lactancia materna y riesgos de no amamantar. Revista chilena de pediatría, 88(1), 07-14. https://scielo.conicyt.cl/scielo. php?script=sci_arttext $\&$ pid $=$ S 0370-41062017000100001

Carrillo, M., Tello, G., Navarrete, N. (2016). Relación de la succión no nutritiva con la maloclusión en niños ecuatorianos. Revista "ODONTOLOGÍA". (Vol. 18). p 13 - 19. https://dialnet.unirioja.es/servl et/articulo?codigo $=5597618$

Carvajal, J., Carmiñia, C., Escudero, E., Romero, M. (2015). Prevalencia de hábitos bucales y su relación con las mal oclusiones en niños de edad preescolar pertenecientes a la red 1 de la ciudad de Sucre, 2012. Ciencias de la Salud, Handbook.

Chung, I., Muñoz, L., Veloso, A., Cuadros, C., Guinot, F. (2018). Relación entre la mordida abierta anterior y el hábito de succión digital: revisión sistemática. Odonto Pediatr, 26 (2), 144-154. 
https://www.odontologiapedia trica.com/wp-

content/uploads/2018/07/05

REV_327_Chung.pdf

Cisneros, G., Falcón, E., Padilla, E., Blanco, J. (2015). Hipnoterapia en niños de 7-12 años con succión digital. Revista Biomédica. https://www.medigraphic.com /pdfs/medisan/mds2015/mds155f.pdf

Cisneros, G., y Cruz, I. (2017). Detalles clínicos de la oclusión dental en niños de un círculo infantil. MEDISAN, 21(7), 781-787. http://scielo.sld.cu/scielo.php? pid=S1029$30192017000700002 \&$ script $=$ sci_arttext\&tlng=en

Clínica Silvia Molins. Hábitos que deforman la mordida infantil: el chupete y el biberón. https://www.clinicasilviamolin s.com/habitos-que-deformanla-mordida-infantil-el-chupetey-el-biberon/

Crespo C, Carrasco J, Ramírez M, Chicaiza H. (2020). Prevalencia de hábitos orales $y$ sus consecuencias dentomaxilares en escolares. https://killkana.ucacue.edu.ec /index.php/killcana_salud/arti cle/view/330

Díaz, H., Ochoa, B., Paz, L., Casanova, K., Coca, Y. (2015). Prevalencia de maloclusiones en niños de la escuela Carlos Cuquejo del municipio Puerto Padre, Las

Tunas. Medisur 13(4). http://www.medisur.sld.cu/ind ex.php/medisur/article/view/2 848

Dickmar, B., Hernández, M., Guerra, M. (2015). Relación entre periodo de amamantamiento y la presencia de hábitos nocivos en niños Venezolanos. Revista de Odontopediatría Latinoamericana.

Espinoza, I., Casas, L., Campos, K. (2016). Prevalencia de hábitos orales y alteraciones dentoalveolares en niños de 6 a 12 años. http://51.79.74.182/index.php/ odontologiapediatrica/article/v iew/61/63

Fernández, E. (2020). Lactancia materna: cómo valorar su inicio. Centro de salud de Vitigudino. Unidad de Lactancia Materna del área de Salamanca.

https://www.pediatriaintegral. es/wpcontent/uploads/2020/xxiv02/ 01/n2-071080_EncarnaFdez.pdf

Galeano, G. Mocha, S. Osorio, S. López, D., Tobón, F., Agudelo, A. (2013). Oclusión y hábitos bucales en niños de 5 a 12 años de una institución educativa de Medellín; 2012. Revista Nacional de Odontología. 
Gálvez, M., Ramos, I., Jiménez, L. (2018). Acciones educativas sobre hábitos bucales deformantes en escolares de primaria. Medicentro Electrónica. (Vol. 23). http://scielo.sld.cu/scielo.php? script=sci_arttext\&pid=S1029 $-30432018000300012$

García, V. J., Ustrell, J. M., Sentís, J. (2014). Evaluación de la maloclusión, alteraciones funcionales y hábitos orales en una población escolar: Tarragona y Barcelona.

González, L., Mena, G., Sarmientos, Y., Durán, W., Romero, L. (2018). Anomalías dentomaxilofaciales de la atención primaria de salud en escolares de 6-12 años. Multimed. Revista Médica.

González, X., Cardentey, J., Porras, O., Pérez, K., González, R. (2019). Conocimientos en embarazadas sobre beneficios de la lactancia materna para salud bucal del futuro bebé. Revista Archivo Médico de Camagüey, 23(5), 604-616.

Hechavarría, B., Núñez, L., Pérez, Y., Pons, B., Núñez, N. (2020). Caracterización en niños de 4 a 6 años con interferencias dentarias de círculos infantiles. https://www.aulavirtualusmp.p e/ojs/index.php/RevKiru0/article/view/1839/2003
Hernández E, Rodríguez M I, Contreras A S, García E. (2015). Las mordidas abiertas anteriores en pacientes de 9 a 14 años de edad. Rev cienc médicas 19(5):820-9. http://www.revcmpinar.sld.cu/i ndex.php/publicaciones/articl e/view/2227

Herrero, Y. y Arias, Y. (2019). Hábitos bucales deformantes y su relación etiológica con las maloclusiones. (Vol. 23). Multimed.

http://scielo.sld.cu/scielo.php? script=sci_arttext\&pid=S1028 $-48182019000300580$

Iglesias, S., Bencomo, M., Camargo, E., Sarrías, D. (2016). Prevalencia de maloclusiones en pacientes del Policlínico Elena Fernández Castro del municipio Los Palacios. Univ Méd 12(2). http://www.revgaleno.sld.cu/in dex.php/ump/article/view/193

Letini, D., Carvalho F., Garcia, C., Ye, Q., Hu, R., Minami, H., Carvalho, L., Prado, L., Prado, G. (2015). Tratamiento de ortodoncia y ortopedia para mordida abierta anterior en niños. Base de datos Cochrane de revisiones sistemáticas.

Lima, M., Rodríguez, A., García, B. (2019). Maloclusiones dentarias y su relación con los hábitos bucales lesivos. Revista Cubana de Estomatología. https://www.medigraphic.com 
/pdfs/revcubest/esc2019/esc192i.pdf

Lópes, G. (2017). La relación entre los diferentes tipos de lactancia materna, los hábitos de succión no nutritiva y la oclusión en un grupo de niños de 3 a 6 años de edad. https://www.tdx.cat/handle/10 803/461946\#page $=1$

López, Y. (2016). Función motora oral del lactante como estímulo de crecimiento craneofacial. Universitas Odontológica, vol. 35, núm. 74, pp. 1-37. Pontificia Universidad Javeriana. Bogotá, Colombia. https://pdfs.semanticscholar.o $\mathrm{rg} / \mathrm{cdf} 4 / \mathrm{ab} 5 \mathrm{df} 8 f a f 362 \mathrm{e} 90 \mathrm{~d} 42 \mathrm{~b}$ 0cf1d4950327ae315.pdf

Martínez, M., George, Y., Llópiz, Y., Pérez, B., Bosch, L. (2017). Características de la oclusión dentaria en niños de 4 y 5 años. MEDISAN, 21(11), 3221-3226.

http://scielo.sld.cu/scielo.php? pid $=$ S1029-

$30192017001100011 \&$ script $=$ sci_arttext\&tIng=pt

Mena, D., y Sánchez, J. (2019). Uso del chupete y efectos sobre la salud: una revisión de la literatura. Ediciones ROL. Universitat Jaume I. http://repositori.uji.es/xmlui/bit stream/handle/10234/182305 163956.pdf?sequence $=1$ \&isAll owed $=\mathrm{y}$
Méndez, Y., Peña, Y., Lagoa, J., Batista, T., Carracedo, Z. (2017). Factores de riesgo asociados a hábitos bucales deformantes en niños. (Vol. 21). Correo Científico Médico. http://scielo.sld.cu/scielo.php? script=sci_arttext\&pid=S1560 $-43812017000300006$

Mendoza, A. y Tovar E. (2018). Lactancia materna. Su influjo en las malas oclusiones en niños escolares. Dominio las Cienc.

https://www.dominiodelascien cias.com/ojs/index.php/es/arti cle/view/744/html

Mendoza, A., Tovar, E. Robles, I. (2017). Lactancia materna. Su influjo en las malas oclusiones en niños escolares. Revista Dominio de las Ciencias, 4(1). https://dominiodelasciencias.c om/ojs/index.php/es/article/vi $\mathrm{ew} / 744$

Mendoza, P., Méndez, J., Florentín, D., Martínez, G., Aguilar, G., Ríos, C. (2019). Prevalencia de hábitos de succión no nutritiva y su relación con maloclusión y anomalías dentomaxilares en preescolares de Cnel. Oviedo, Paraguay. Memorias del Instituto de Investigaciones en Ciencias de la Salud, 17(3), 49-54.

Meneses, E., Vivares, A., Rodríguez M. J. (2015). Perfil epidemiológico de la oclusión estática y los hábitos orales en un grupo de escolares de 
Medellín, Colombia. Rev Nac Odontol, 12(22):69-79.

Mesa, N. y Medrano, J. (2017). Hábitos bucales deformantes y maloclusiones en niños del Policlínico Máximo Gómez. http://www.revcocmed.sld.cu/i ndex.php/cocmed/article/view /2331

Ministerio de Salud Pública del Ecuador. (2015). Propuesta para el fortalecimiento institucional en el área de nutrición en salud. http://instituciones.msp.gob.e c/dps/pichincha/images/storie s/documentos/nutricion_en_s alud.pdf

Mora, C., Álvarez, I., Blanco, A., Espino, Y., Morera, A., Macías, A. (2017). Efectividad de la Intervención en niños de 5 a 11 años portadores de hábitos bucales deformantes. Rev nac odontol 13(25). http://dx.doi.org/10.16925/od. v13i25.1884

Morera, A., Sexto, N., Yanes, B., Casanova, A. (2016). Intervención educativa sobre factores de riesgo asociados a maloclusiones en niños de cinco años. MediSur, 14(2), 143-153.

Moscardini, M., Díaz, S., De Rossi, M., Filho, P., De Rossi, A. (2017). Odontología para bebés: una posibilidad práctica de promoción de salud bucal. https://www.revistaodontoped iatria.org/ediciones/2017/2/art $-5 /$

Muller, R. y Piñeiro, S. (2015). Malos hábitos orales: rehabilitación neuromuscular y crecimiento facial. Revista Médica Clínica Las Condes. (Vol. 25). p 380 388.

https://www.sciencedirect.co $\mathrm{m} /$ science/article/pii/S071686 4014700501

Nieto K G, Mendoza M, Pontigo A P. (2017). Prevención de hábitos no fisiológicos a través de la lactancia materna. Educ Salud Bol Cient Cienc Salud ICSa;5(9). http://dx.doi.org/10.29057/ics a.v5i9.2253

Núñez, M., González, O., Martínez, Y., Madam, M. (2015). Determinar los hábitos bucales deformantes en estudiantes de la Escuela Primaria "Raúl Gómez", municipio Güines. Revista de Ciencias Médicas La Habana. (Vol. 21).

Ochando, F. (2019). Malos hábitos orales.

https://clinicadentalbarrutia.co $\mathrm{m} /$ cuidadodental/201901/malos-habitosorales/

Osorio, V. y Mora, J. (2019). Anomalías dentofaciales a causa del hábito de succión digital que prevalecen en niños menores a 5 años de edad. Revista Científica 
"Especialidades

Odontológicas UG”.

Parra, S. S., y Zambrano, A. G. (2018). Hábitos Deformantes Orales en Preescolares y Escolares: Revisión Sistemática.

https://scielo.conicyt.cl/scielo. php?script=sci_arttext\&pid=S 0718-

$381 \times 2018000200188 \& \operatorname{lng}=e n$ \&nrm=iso\&tlng=en

Paz, M. (2015). Lactancia materna y su contribución al adecuado desarrollo del sistema estomatognático y sus funciones. Revista Signos Fónicos.

revistas.unipamplona.edu.co/ ojs_viceinves/index.php/CDH/ article

Pérez, D. (2021). Factores de riesgo y Diagnóstico de maloclusiones en niños de 5 a 11 años. https://polodelconocimiento.c om/ojs/index.php/es/article/vi ew/433/pdf

Pinheiro, G., y Chollopetz, M. (2015). Prevención y manejo del dolor farmacológico en recién nacidos. Revista Brasileña de Enfermería. (Vol. 65) https://www.scielo.br/scielo.p hp?script=sci_arttext\&pid=S0 034-

$71672015000100131 \& \operatorname{lng}=\mathrm{pt}$ \&tlng $=p t$

Polanco, Y., Pérez, D., Alcolea, J. (2019). Cultura sanitaria sobre hábitos bucales deformantes relacionados con el micrognatismo transversal superior. Escuela "Ciro Redondo". Multimed. (Vol. 23).

Puga, P., Gálvez, D., Sanz, L. (2015). Influencia de la lactancia materna en la prevención de anomalías dentales y maxilofaciales. Revisión bibliográfica.

Ramos, R., Acosta, I., Giralt, M., Díaz, J. (2016). Programa Educativo en escolares de 1er y 2do grado con hábito de succión digital. Acta Odontol Colomb.

(1):21-31. https://revistas.unal.edu.co/in dex.php/actaodontocol/article/ view/58844

Reyes, D., Paneque, M., Almeida, Y., Quesada, L., Escalona, D., Torres, S. (2015). Factores de riesgo asociados a hábitos bucales deformantes en niños de 5 a 11 años: estudio de casos y controles. Medwave.

Rivera S., Varriga S., García Alejandro., Espinoza J. (2019). Hábitos que promueven maloclusiones en infantes. Revista Latinoamericana de Ortodoncia y Odontopediatría. https://www.ortodoncia.ws/pu blicaciones/2019/art-12/

Rodríguez, A., Martínez B., Rodríguez, B. (2019). Influencia de la lactancia materna en los diastemas fisiológicos de crecimiento. 
Rev Méd Electrón. https://www.medigraphic.com /pdfs/revmedele/me2018/me185g.pdf

Rodríguez, J., Fuentes, R., Arévalo, Y. (2017). Factores de riesgo en el aparecimiento de enfermedades bucales y su relación con la lactancia materna en mujeres de la comunidad San Isidro los planes.

http://dx.doi.org/10.5377/crea ciencia.v11i1-2.6121

Rodríguez, N., Horta, D., Vences, N. (2017). Tratamiento de hábitos deformantes bucales en niños de 4 a 13 años con auriculoterapia. Revista Archivo Médico de Camagüey. (Vol. 21).

Rondón, R. G., Zambrano, G. A., Guerra, M. E., Rodríguez de Galarraga, B. (2021). Relación entre un periodo de lactancia materna exclusiva menor de 6 meses y presencia de hábitos parafuncionales en un grupo de niños y adolescentes venezolanos. Revista De Odontopediatría

Latinoamericana, 8(1), 13. https://www.revistaodontoped iatria.org/index.php/alop/articl e/view/133/63

Salamanca T, y Murrieta J. (2015). Frecuencia de alteraciones en la oclusión en dentición primaria y su asociación con algunos hábitos bucales parafuncionales en un Jardín de niños del Estado de México. https://www.redalyc.org/pdf/3 242/324243574002.pdf

Sánchez, N., Suárez, O., Navarro, N., González A. (2017). Diámetro transversal del maxilar y hábitos bucales perjudiciales en la lactancia materna. Rev cienc médicas Pinar Río. 21(2):257-65. http://www.revcmpinar.sld.cu/i ndex.php/publicaciones/articl e/view/2874

Segura, N., Medrano, J., Moreira, F., Segura, N., Terán, S. (2017). Prevalencia de mordida cruzada en pacientes de la Clínica Estomatológica Artemio Mastrapa. http://www.revcocmed.sld.cu/i ndex.php/cocmed/article/view /2381

Serrano, K., Arévalo, N., Hernández, L., Serrano, K., Arévalo, N., Hernández, L. (2019). El conocimiento sobre salud bucal de padres y maestros de la Escuela especial La Edad de Oro.

Solís, M. (2018). Succión digital: repercusiones y tratamiento. http://www.op.spo.com.pe/ind ex.php/odontologiapediatrica/ article/view/21/22

Torres, M., Barberán, Y., Bruzón, A., Figueredo, E., Rosales, Y., (2017).

Factores predisponentes de trauma dental en escolares del municipio Rafael Freyre. 
http://scielo.sld.cu/scielo.php?

script=sci_arttext\&pid=S1560

$-43812017000300016$

Veliz, C., Ponce, R., Delgado, C. (2018). Ciertas características del estado de la oclusión en niños escolares. Polo del Conocimiento. 3(1):214-24. https://polodelconocimiento.c om/ojs/index.php/es/article/vi ew/425 